\title{
Apparent effect of immune serum globulin prophylaxis in the military on viral hepatitis incidence in the civilian population in Israel
}

\author{
MANFRED S GREEN AND COLIN BLOCK \\ From the Medical Corps Headquarters, Israel Defence Force, Israel
}

\begin{abstract}
Since 1969, extensive use of immune serum globulin in the Israel Defence Force for prophylaxis against hepatitis A virus (HAV) infection has produced a sharp decline in the incidence of the disease. However, it is not clear whether this policy has affected the susceptibility of Israeli adults to HAV infection. In this study, we examined the effect of the immunisation policy on the incidence of hepatitis A virus infection in the civilian population in the 15-44 year age group, which includes all those who have completed compulsory military service since vaccination was introduced. The incidence of viral hepatitis in the Jewish civilian population aged 15-44 increased by approximately $50 \% 3-4$ years after the implementation of the immunisation policy. This rise was not seen in the non-Jewish population of the same age nor among Jews aged 45-64. These findings strongly suggest that the immunisation policy in the military prevents both clinical and sub-clinical disease, but has had the effect of producing more susceptible people at an older age in the civilian population.
\end{abstract}

Hepatitis A virus (HAV) infection is endemic in Israel $^{1}$ and studies in the military population have shown it to be the cause of more than $80 \%$ of all clinical cases of viral hepatitis. ${ }^{2}$ The highest incidence is generally from late summer to mid winter. In 1969 the Medical Corps of the Israel Defence Force (IDF) instituted a policy of intensive surveillance for hepatitis A virus infection and administered immune serum globulin (ISG) to suspected contacts. ${ }^{3}$ In 1977 , this policy was extended to the annual prophylactic administration of $5 \mathrm{ml}$ of pooled ISG to a large segment of the military population. ${ }^{4}$ In general, most conscripts receive ISG at the start of their compulsory military service (3 years for men and 2 years for women) and those serving in field units receive annual ISG prophylaxis. In addition, if it is suspected that soldiers have been exposed to a case of HAV infection and more than 5-6 months have passed since their last immunisation, a further injection of $2 \mathrm{ml}$ ISG is given.

Controlled studies have shown that the immunisation policy has been highly effective in reducing the incidence of $\mathrm{HAV}$ infection among soldiers and has almost eliminated the occurrence of epidemics of the disease. ${ }^{45}$ As a result of this policy, a fairly large segment of the Jewish population between the ages 18-21 years is protected by ISG for at least part of the year. (In general, the non-Jewish population is not required to serve in the IDF.) It has been noted that a single dose of $5 \mathrm{ml}$ ISG appears to provide complete protection against clinical HAV infection for at least 6 months, and at least partial protection for between 6 months and 1 year after injection. ${ }^{4}$ This extended protection was observed using pooled ISG of North American origin, and therefore could not be ascribed to increased efficacy of a local product. It is conceivable that this prolonged effect simply reflected a gradual decline in the protection conferred by ISG during the 6-12 month period after injection.

It has frequently been questioned whether the reduced incidence of clinical HAV infection in the IDF reflects a suppression of the clinical manifestations of the disease without affecting seroconversion, or whether the disease is prevented both clinically and serologically. In general there have been conflicting views as to whether ISG prophylaxis modifies the symptoms of the disease without suppressing the immune response ("passive-active immunisation"), or whether seroconversion is also prevented. $^{6}$ Early investigators believed that the phenomenon of passive-active immunisation was responsible for the prolonged period of protection provided by ISG. ${ }^{78}$ However, recent studies have indicated that passive-active immunisation may be relatively rare. ${ }^{910}$ 
One approach to examining this question would be to compare anti-HAV antibody prevalence at the end of military service between previously immunised and unimmunised soldiers. Since most conscripts receive ISG at some time during their military service, it is extremely difficult to identify a suitable unimmunised comparison group with similar sociodemographic characteristics and risk of exposure to HAV. Thus the question was addressed in this study from another angle by examining the effects of the immunisation policy in the IDF on the incidence of hepatitis in the civilian population.

Infectious hepatitis is not reported according to the specific aetiological agent. Thus, no direct data exist on the relative frequency of the different types of viral hepatitis apart from those derived from the military study. ${ }^{2}$ However, there is much indirect evidence to suggest that the majority of infectious hepatitis cases in Israel are due to HAV. ${ }^{1}$ Sandler $e t$ al, ${ }^{11}$ found that hepatitis B virus accounted for only $27 \%$ of infectious hepatitis cases among adults admitted to a large Israeli hospital, even though hepatitis B cases are generally more likely to be admitted to hospital than those with hepatitis A infection.

In the present study, the age specific incidence of viral hepatitis in the civilian population was examined both prior to and after the introduction of the immunisation policy in the IDF. We reasoned that if ISG prophylaxis prevented both symptoms of hepatitis $A$ and seroconversion, then in the years following the implementation of the policy, there would be a stepwise increase in the proportion of susceptibles in the civilian population reflected by a parallel increase in the incidence of the disease.

\section{Methods}

Infectious hepatitis is a notifiable disease both in the civilian and military populations in Israel. The incidence of infectious hepatitis in the civilian population was extracted from publications of the Ministry of Health's Department of Epidemiology for the period 1963 to 1985 . The IDF maintains a separate, similar reporting system for the military population and data were obtained for the same period. In the IDF, reporting of suspected hepatitis to the central epidemiology unit is compulsory. All cases are admitted to hospital and during this period they are interviewed by an epidemiology officer. As a result of this policy, the data on clinical hepatitis in the military population are believed to be almost complete.

The rates for the civilian population were computed using the average annual population as the denominator. For the military population, the rates were computed with both the numerator and denominator derived from all soldiers in regular service (compulsory and permanent). It should be noted that the annual rates for civilians are reported for the calendar year (January to December) whereas those for the military are reported for the year beginning on the 1st April. Secular (long term) trends in incidence were examined by means of linear regression.

\section{Results}

Overall incidence rates in the Jewish civilian population and the military population between 1963 and 1985 are given in fig 1 . The incidence declined steeply in the military population from 1970 following



Fig 1 Incidence of hepatitis per 1000 in the civilian and military populations in Israel between the years 1963 and 1985.

the implementation of post-exposure administration of ISG and dropped even further from 1978 following expansion of the policy to pre-exposure ISG prophylaxis. During the same period there was an increase in the incidence in the civilian population from about 0.8 per 1000 to about 1.2 per 1000 .

Incidence rates for hepatitis for the civilian Jews aged 15-44 and 45-64 years and for non-Jews aged 15-44 years are given in fig 2 . The incidence over the whole period under study (1963-85) increased significantly among Jews in the 15-44 age group (the regression analysis yielded $\beta=0.009, \mathrm{SE}=0.003$, $R^{2}=0.37$ ), whereas there was no evidence of such an increase in the 45-64 age group $(\beta=-0.001$, $\mathrm{SE}=0.001, \mathrm{R}^{2}=0.08$ ) nor among non-Jews in the 15-44 age group $\left(\beta=-0.001, S E=0.001, R^{2}=0.03\right)$. However, on further examination the incidence among Jews aged 15-44 could be divided into two distinct periods, 1963-75 and 1976-85. During each of these periods there was essentially no increase in incidence $(\beta=-0.005, \mathrm{SE}=0.005$, and $\beta=0.005$, $\mathrm{SE}=0.005$ with $\mathrm{R}^{2}=\mathbf{0 . 0 8}$ for each period), indicating 


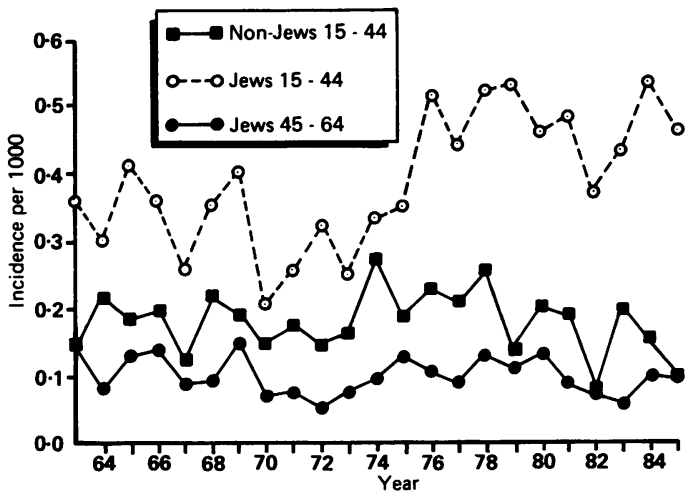

Fig 2 Incidence of hepatitis per 1000 in the Jewish and non-Jewish civilian populations aged 15-44 and the Jewish population aged 45-64 in Israel between the years 1963 and 1985.

a stepwise increase in incidence around 1975-6. Incidence rates for the Jewish civilian population in the age groups 15-24 and 25-44 were available from 1971 only and are given in fig 3. These graphs show that those in the 25-44 age group were mainly responsible for the increase in incidence in the 15-44 age group following 1975 .



Fig 3 Incidence of hepatitis per 1000 in the Jewish civilian population aged 15-24, 25-44 and 45-64 in Israel between the years 1971 and 1985.

\section{Discussion}

The results of the present study tend to support the hypothesis that the decline in the incidence of HAV infection in the military due to the extensive use of ISG prophylaxis may have been at the expense of an increased incidence in the civilian population in the age group which has just completed compulsory military service. These data also lend weight to the view that the use of ISG to prevent HAV infection effectively prevents both the clinical manifestations of the disease and serological response to the virus.

The mode of action of ISG has been assumed to be through transfer of neutralising antibodies and it has been suggested that if the HAV antibody titre is sufficiently high, then the disease will be prevented completely. ${ }^{12}$ If not, then only the symptoms will be suppressed and passive-active immunity will take place. Early investigators suggested that a large measure of passive-active immunisation occurs ${ }^{78}$ and passive-active immunity has been shown in animals. ${ }^{7}$ In a large study of US soldiers in Korea, symptoms of HAV infection were slightly milder in those who received ISG than those who received placebo. ${ }^{13}$

One of the problems in evaluating possible passiveactive immunity is the difficulty in distinguishing between simple subclinical infection which may occur with or without immunisation, and seroconversion occurring under cover of passive immunisation with suppression of clinical manifestations. ${ }^{14}$ This question could only be addressed conclusively in a controlled trial where subclinical rates among immunised and non-immunised subjects are compared.

The observations in this study are based on trends in the incidence of reported disease and cannot be interpreted as providing evidence of a cause-effect relationship. Furthermore one cannot exclude the possibility that the use of ISG may produce a certain measure of herd immunity in the military, which may contribute to the reduced incidence of HAV infection in this population. ${ }^{15}$ However, from an unusual perspective, the findings do lend weight to the evidence that ISG prophylaxis, given in the recommended dose and in a preparation containing adequate anti-HAV antibody titre, prevents both clinical and subclinical infection. This observation has implications for travellers spending long periods in endemic areas and receiving repeated doses of ISG. They may be unlikely to develop passive-active immunity and will therefore be susceptible to the disease on cessation of immunisation. ${ }^{16}$ This should be stressed in recommendations to such travellers.

Address for correspondence and reprints: Dr Manfred Green MD, PhD, Military Post 02149, Israel Defence Force, Israel.

\section{References}

${ }^{1}$ Swartz TA, Levin J, Ben Porat E. Epidemiology of hepatitis A in Israel. Monogr Virol 1984; 15: 53-8.

2 Matzkin H. Epidemiologic features of acute viral hepatitis among the Israeli Defence Forces, 1977-83. J Infect 1987; 14: 271-8. 
${ }^{3}$ Naggan L, Egoz N, Kark JD. Role of epidemiologic surveillance in military populations in peace-time. Int Rev Army Navy Air Force Med Service 1975; 48: 189-91.

${ }^{4}$ Kark JD, Witztum E, Mazkin H, Nili E, Danon YL. The three-year incidence of non-B viral hepatitis morbidity in a controlled trial of pre-exposure immune serum globulin prophylaxis. Infection 1984; 12: 251-5.

${ }^{5}$ Matzkin H. Acute non-B hepatitis in the Israel Defence Forces. Hepatology 1987; 7: 1330-2.

${ }^{6}$ Robinson WS. Hepatitis A virus. In: Mandell GL, Douglas RG, Bennett JE, eds. Principles and practice of infectious diseases. New York: John Wiley, 1985: 829-40.

${ }^{7}$ Stokes J, Farquar JA, Drake ME, Capps RB, Ward CS, Mills $O$. Infectious hepatitis. Length of protection by immune serum globulin during epidemics. JAMA 1951; 147: 714-9.

${ }^{8}$ Krugman S, Ward R, Giles JP, Jacobs AM. Infectious hepatitis. Studies on the effect of gamma globulin and on the incidence of inapparent infection. $J A M A 1960 ; 174$ : 823-30.

${ }^{9}$ Weiland O, Niklasson B, Berg R, Lundbergh P, Tidestrom L. Clinical and subclinical hepatitis A occurring after immunoglobulin prophylaxis among Swedish UN soldiers in Sinai. Scand J Gastroenterol 1981; 16: 967-82.

10 Green MS, Dotan K. Efficacy of immune serum globulin in an outbreak of hepatitis A in adults. J Infect 1988; 17: 265-70.
11 Sandler SG, Shouval D, Marcus M, et al. Viral hepatitis type B and non-B in Jerusalem. Bull WHO 1976; 54: 193-8.

12 Seeff LB, Hoofnagle JH. Immunoprophylaxis of viral hepatitis. Gastroenterology 1979; 77: 161-82.

13 Cooperative Study. Prophylactic gamma globulin for prevention of endemic hepatitis. Effects of US gamma globulin upon the incidence of viral hepatitis and other infectious diseases in US soldiers abroad. Arch Intern Med 1971; 128: 723-38.

${ }^{14}$ Rakela J, Nugent E, Mosley JW. Viral hepatitis: enzyme assays and serologic procedures in the study of an epidemic. Am J Epidemiol 1977; 106: 493-501.

$15 \mathrm{Kark}$ JD. Pre-exposure prophylaxis of viral hepatitis with immune serum globulin in an endemic area. A trial in field units of the Israel Defence Forces. Scand J Infect Dis 1983; 15: 3-6.

${ }^{16}$ Woodson RD, Cahill KM. Viral hepatitis abroad. Incidence in Catholic missionaries. JAMA 1972; 219: 1191-3. 